\title{
Analisis Satua I Ubuh dengan Satua Bagus Diarsa (Teks Perbandingan)
}

\author{
Ni Putu Ayu Desi Yanti ${ }^{1}$, Wayan Suteja ${ }^{2}$, Ni Made Suryati ${ }^{3}$ \\ ${ }^{[123]}$ Prodi Sastra Bali Fakultas Ilmu Budaya Universitas Udayana \\ [1desiayu2794@yahoo.com] ${ }^{2}$ [wayansuteja80@yahoo.com] \\ 3 [suryati.jirnaya@yahoo.com] \\ *Coresssponding Author
}

\begin{abstract}
Abstrak
Penelitian ini menganalisis dua buah karya sastra bentuk prosa lisan yaitu Satua I Ubuh dan Satua Bagus Diarsa, untuk dapat memahami dan menggali lebih dalam mengenai kehadiran teks dalam teks lain atau hubungan intertekstual yang terdapat antara Satua I Ubuh dengan Satua Bagus Diarsa. Penelitian ini berlandaskan pada teori struktural dari pandangan Teeuw dan teori interteks pada pandangan Kristeva, Tahap pengumpulan data menggunakan metode wawancara bebas terarah dibantu dengan teknik rekam, pencatatan, teknik transkripsi dan teknik terjemahan. Tahap analisis data menggunakan metode kualitatif dibantu dengan teknik deskriptif analitik. Tahap penyajian hasil analisis data menggunakan metode informal dibantu dengan teknik deduktif dan induktif. Hasil yang diperoleh dalam penelitian ini terungkap struktur membentuk dari Satua I Ubuh dan Satua Bagus Diarsa yang masing-masing meliputi insiden, alur pada kedua satua ini alur maju, tokoh dan penokohan meliputi tokoh utama, tokoh sekunder, dan tokoh komplementer, latar kedua satua ini latar waktu, tempat, dan suasana, tema kedua satua ini yaitu Satya Samaya, serta amanat. Di samping itu penelitian ini juga terungkap hubungan intertekstual antara Satua I Ubuh dengan Satua Bagus Diarsa yang menggunakan motif yang sama yaitu sarana bulu ayam untuk menuju arah dan tempat. Sedangkan perbedaan antara kedua satua ini yaitu I Santeng pergi ke arah tenggara menuju dasar laut, tetapi I Bagus Diarsa pergi ke arah utara menuju pohon beringin.
\end{abstract}

Kata Kunci: satua, struktur, dan intertekstual.

\begin{abstract}
This study discussed two literary works of oral prose namely I Ubuh story and Bagus Diarsa story, which aims at understanding and investigating the existence of a text in another text or the intertextual relation in the story of I Ubuh and Bagus Diarsa. This study is conducted based on the structural theory from Teeuw and intertext theory from Kristeva, while the data collection is done by using free guided interview and supported by recording technique, taking notes, transcription and translation techniques. The methods used in analyzing the data are qualitative method and descriptive analytic method. In presenting the data analysis, the method used is informal method supported by deductive and inductive techniques. The findings of this study show that there are structures which form the story of I Ubuh and Bagus Diarsa namely incident; chronological plot in the stories; characters and characterizations such as main character, secondary figures, and complementary characters; the settings of both stories are setting of time, place and situation; the theme of the stories is Satya Samaya; and the moral. Besides, the findings show that there is intertextual relation between the story of I Ubuh and Bagus Diarsa, they have the similar motives namely chicken
\end{abstract}


feathers that used to show directions and places in the stories. Meanwhile, the difference between these stories is I Santeng went southeast to reach the sea floor, and I Bagus Diarsa went north to reach the Banyan Tree.

Key Words: story, structure, and intertextual

\section{Latar Belakang}

Satua adalah istilah dalam bahasa Bali untuk menunjuk karya jenis dongeng. Dongeng adalah cerita prosa rakyat yang tidak dianggap benar-benar terjadi. Dongeng diceritakan terutama untuk hiburan, walaupun banyak juga yang melukiskan kebenaran, pelajaran (moral), atau bahkan sindiran (Danandjaja, 1984: 83-84). Satua menurut I Gst. Ngurah Bagus (1986: 4) yaitu cerita prosa lisan yang diturunkan dari mulut ke mulut secara turun-temurun dari satu generasi ke generasi berikutnya. Jadi, satua merupakan salah satu karya sastra Bali Purwa yang berbentuk prosa yang diwarisi secara lisan. Satua dapat dikatakan memiliki multi fungsi, yaitu sebagai sarana hiburan, pendidikan karena selain terdapat unsur imajinatif juga sarat akan pesan atau amanat yang berguna bagi kehidupan. Penggolongan satua Bali dapat dibagi menjadi dongengdongeng jenaka (Satua Banyol), dongeng panji (Satua Panji), dongeng biasa (kisah hidup seseorang) dan lainnya, Satua Tantri merupakan cerita berantai yang menampilkan berbagai jenis binatang sebagai tokoh sentral dalam setiap episode. Pada kesempatan ini diteliti dua buah satua yang tergolong dongeng biasa, yaitu Satua I Ubuh dan Satua Bagus Diarsa. Satua I Ubuh merupakan satua yang hidup di Desa Baluk Kecamatan Negara Kabupaten Jembrana, sedangkan Satua Bagus Diarsa merupakan kumpulan satua pada buku Kembang Rampe Kesusastraan Bali Purwa volume 1 yang dikarang oleh I Gusti Ngurah Bagus, I Ketut Ginarsa, pada bagian 16 dimulai dari halaman 82 sampai halaman 88. Unsur sastra kedua satua tersebut sama seperti unsur karya fiksi bentuk prosa secara umum yaitu terdiri dari insiden, alur, tokoh dan penokohan, latar, tema, dan amanat. Persamaan yang paling menonjol dari kedua satua ini yaitu motif ceritanya yang sama-sama menceritakan menggunakan bulu ayam sebagai penunjuk rumah, kedewaan, dan kepolosan seorang anak laki-laki yang menghasilkan kejayaan. Unsur-unsur utama yang paling khas dari motif satua ini adalah bulu ayam. Perbedaan yang terdapat dalam Satua I Ubuh dengan Satua Bagus Diarsa, yaitu dalam Satua I Ubuh digambarkan bahwa I Santeng menuju arah tenggara menuju laut, sedangkan pada Satua Bagus Diarsa pergi menuju arah utara menuju gunung.

\section{Pokok Permasalahan}

Berdasarkan latar belakang yang telah diuraikan di atas, maka pada penelitian ini akan disajikan dalam bentuk pertanyaan sebagai berikut.

1) Bagaimanakah struktur Satua I Ubuh dan Satua Bagus Diarsa?

2) Bagaimanakah hubungan intertekstual antara Satua I Ubuh dengan Satua Bagus Diarsa?

\section{Tujuan Penelitian}

Setiap penelitian yang dilakukan sudah tentu mempunyai tujuan yang ingin dicapai. Demikian pula halnya dalam penelitian ini. Tujuan penelitian ini, secara garis besar dibagai menjadi dua, yaitu (1) tujuan umum dan (2) tujuan khusus. Keduanya diuraikan sebagai berikut.

\section{Tujuan Umum}

Secara umum penelitian terhadap Satua I Ubuh dan Satua Bagus Diarsa ini 
bertujuan untuk membina, melestarikan, dan mengembangkan karya-karya sastra tradisional sebagai warisan budaya bangsa dalam upaya pembinaan dan pengembangan kebudayaan nasional melalui pengembangan kebudayaan daerah. Selain itu, untuk menambah khazanah penelitian sastra khususnya terhadap satua Bali.

\section{Tujuan Khusus}

Berdasarkan rumusan masalah diatas, tujuan khusus dalam penelitian ini dapat dirumuskan sebagai berikut:

1. Untuk mengetahui struktur Satua I Ubuh dan Satua Bagus Diarsa.

2. Untuk mengetahui hubungan intertekstual antara Satua I Ubuh dengan Satua Bagus Diarsa.

\section{Metode dan Teknik}

\section{Metode dan Teknik Penelitian}

Penelitian berupa karya sastra, memerlukan sebuah metode. Metode berasal dari kata methodos (bahasa Latin) yang berasal dari akar kata meta dan hodos. Meta berarti menuju, melalui, sedangkan hodos berarti jalan, cara. Metode dianggap sebagai cara-cara atau strategi untuk memahami realitas, langkah-langkah sistematika untuk memecahkan rangkaian sebab akibat berikutnya. Sama halnya dengan teori, metode adalah cara yang digunakan untuk menyederhanakan masalah dalam suatu penelitian, sehingga lebih mudah untuk dipecahkan dan dipahami (Ratna, 2004:34).

\subsubsection{Metode dan Teknik Pengumpulan Data}

Penelitian ini mengunakan data lisan primer dalam Satua I Ubuh, untuk mendapatkan data lisan primer digunakan metode wawancara. Kedua, metode di atas dibantu dengan teknik rekam dan catat. Proses pengkongkritan belum tuntas bila data primer belum diwujudkan dalam bentuk tulisan. Maka data primer yang masih berupa hasil rekaman tadi kemudian ditranskripsikan. Setelah hasil rekaman ditranskripsikan dan diketik kemudian ditunjang dengan teknik terjemahan, untuk membantu pemahaman terhadap data yang dijadikan objek.

\section{Metode dan Teknik Analisis Data}

Tahap analisis data merupakan lanjutan dari tahap pengumpulan data dengan memeriksa data yang telah terkumpul, data kemudian dianalisis menggunakan metode kualitatif. Metode kualitatif merupakan metode yang memberikan perhatian terhadap data ilmiah yang mempunyai hubungan dengan konteks keberadaannya. Teknik yang digunakan pada tahap analisis data, yaitu teknik deskriptif analitik. Secara etimologis deskripsi dan analisis berarti menguraikan.

\section{Metode dan Teknik Penyajian Hasil Analisis Data}

Adapun metode yang digunakan dalam tahap penyajian hasil analisis data ini yaitu metode informal. Teknik yang digunakan pada tahap akhirnya penelitian ini, yaitu teknik induktif dan deduktif. Teknik induktif merupakan suatu proses penalaran yang bergerak dari beberapa ke semua, dari sebagian seluruh, dari hal-hal bersifat khusus kemudian di kemukakan hal-hal yang bersifat umum, sedangkan teknik deduktif merupakan penerapan suatu prinsip umum menuju suatu kesimpulan khusus sebagai penjelas (Tarigan, 1984: 111-112).

\section{Pembahasan}

\section{Sinopsis}

Sinopsis merupakan ringkasan atau garis besar cerita yang menggambarkan 
isi dari Satua I Ubuh dan Satua Bagus Diarsa. Sinopsis bertujuan untuk memudahkan pembaca mengetahui dan memahami secara singkat isi yang ada pada Satua I Ubuh dan Satua Bagus Diarsa. Dapat disimpulkan bahwa sinopsis Satua I Ubuh dan Satua Bagus Diarsa merupakan sebuah ringkasan cerita yang menggambarkan isi secara garis besarnya.

\section{-Insiden-insiden dalam Satua I Ubuh}

Insiden adalah kejadian atau peristiwa yang terkandung dalam cerita, besar atau kecil. Secara keseluruhan insiden-insiden ini menjadi kerangka yang membangun atau membentuk struktur cerita.

Insiden yang terdapat pada Satua I Ubuh di atas, yang merupakan insiden pokok adalah insiden pertama, kedua, keenam, ketujuh, dan kedelapan. Semua insiden tersebut merupakan insideninsiden yang saling berpengaruh dan mendukung dalam pembentukan alur. Selain insiden pokok, dalam Satua I Ubuh juga terdapat satu insiden sampingan yaitu insiden ketiga. Insiden tersebut tidaklah terlalu berpotensi atau berpengaruh dalam pembentukan alur. Dengan kata lain, insiden tersebut tidak langsung menggerakkan jalan cerita. Insiden sampingan merupakan bagian dari pengembangan dari inti cerita dengan tujuan tertentu. Dapat dikatakan insiden ketiga tersebut mengacu pada sisi lain tokoh I Kilap yang memiliki kesaktian atau kekuatan supranatural sehingga dapat menyamar menjadi burung padahal sebenarnya I Kilap tersebut adalah seorang ratu.

\section{-Insiden-insiden dalam Satua Bagus Diarsa}

Insiden yang terdapat dalam Satua Bagus Diarsa, yang merupakan insiden pokok adalah insiden pertama, kedua, keempat, kelima, keenam, kedelapan, kesembilan, dan kesepuluh. Insideninsiden tersebutlah yang paling potensial menggerakkan cerita. Adapun insiden ketiga dan ketujuh tergolong insiden sampingan karena tidak terlalu berpengaruh penting terhadap gerak cerita, dalam artian walau tidak dihadirkan dua insiden tersebut, cerita masih tetap dapat dimengerti atau dengan kata lain tidak ada bagian yang dirasa hilang dalam cerita ini. Insiden sampingan dapat dikatakan sebagai bagian dari pengembangan inti cerita untuk menyampaikan maksud tertentu. Dapat dikatakan dua inisden tersebut mengacu pada aspek sosial masyarakat yang tersirat pada Satua Bagus Diarsa.

\section{-Alur Satua I Ubuh}

Alur ialah sambung-sinambungnya peristiwa berdasarkan sebab akibat. Alur bukan hanya mengemukakan apa yang terjadi, melainkan juga menunjukkan mengapa hal itu terjadi.

Alur Satua I Ubuh merupakan alur maju yang penceritaannya bersifat kronologis yaitu berurutan dari awal, tengah, hingga akhir. Tahapan-tahapan alurnya yaitu diawali tahap situation, tahap generating circumstances, tahap risisng action, tahap climax, dan diakhiri dengan tahap denouement.

\section{-Alur Satua Bagus Diarsa}

Alur Satua Bagus Diarsa merupakan alur maju yang penceritaannya bersifat kronologis yaitu berurutan dari awal, tengah, hingga akhir.

\section{-Tokoh Utama dan Penokohan dalam Satua I Ubuh}

Dilihat dari segi peranan atau tingkat pentingnya tokoh dalam sebuah cerita, ada tokoh yang tergolong penting dan ditampilkan terus-menerus sehingga terasa mendominasi sebagian besar cerita, yang disebut tokoh utama. Ada tokoh-tokoh yang hanya dimunculkan sekali atau beberapa kali dalam cerita, dan itu pun mungkin dalam porsi penceritaan yang relatif pendek, yang ini 
disebut tokoh tambahan (Nurgiyantoro, 2009:176). Tokoh yang akan dianalisis pertama adalah mengenai tokoh utama. Tokoh utama dalam Satua I Ubuh ini yaitu I Santeng sendiri. I Santeng dikatakan sebagai tokoh utama karena tokoh tersebut muncul dari awal hingga akhir cerita.

\section{-Tokoh Sekunder dan Penokohannya \\ Tokoh sekunder pada Satua I Ubuh yaitu I Kilap yang mulanya ia adalah seekor burung besar. I Kilap memiliki sifat yang bijaksana, setia pada ucapan dan janjinya. Tokoh sekunder selanjutnya yaitu punggawa atau pemimpin yang ada di desa I Santeng. Sang pemimpin mempunyai tokoh yang angkuh, sombong, iri hati.}

\section{-Tokoh Komplementer dan Penokohannya}

Tokoh komplementer dalam Satua I Ubuh ini yaitu anak lingsir, penyeroan, idanda mantri, dan krama desa. Tokohtokoh tersebut mendapat porsi kemunculan yang paling sedikit dalam cerita, namun kemunculannya berfungsi dalam melengkapi cerita.

\section{-Tokoh dan Penokohan dalam Satua Bagus Diarsa}

\section{-Tokoh Utama dan Penokohannya}

Tokoh utama dalam Satua Bagus Diarsa adalah Bagus Diarsa sendiri. Tokoh inilah yang mendapat porsi paling banyak diceritakan dari awal hingga akhir cerita.

\section{-Tokoh Sekunder dan Penokohannya}

Pada Satua Bagus Diarsa, tokoh sekunder yaitu sang kakek yang ternyata adalah Ida Batara Siwa. Ketulusan dari I Bagus Diarsa maka Ida Batara Siwa memberikan seekor ayam sakti. Selanjutnya tokoh sekunder yaitu Mèn Putu yaitu istri I Bagus Diarsa yang mempunyai sifat baik dan penurut pada suaminya. Tokoh sekunder berikutnya yaitu Putu Wiracita anak I Bagus Diarsa yang berjelis kelamin laki-laki mempunyai sifat penurut kepada orang tua terlihat pada saat Putu Wiracita tidak menolak perintah ayahnya untuk ikut dengan sang kakek. Tokoh sekunder yang terkahir yaitu Sang Prabu yang mempunyai sifat angkuh dan iri hati.

\section{-Tokoh Komplementer dan Penokohannya}

Tokoh komplementer yang ditemukan dalam Satua Bagus Diarsayaitu orangorang di arena tajen, soroh dagang, soroh kelian muah perbekel, dan para panjak. Mengenai dimensi fisiologis, psikologis, dan sosiologis dari tokoh-tokoh komplementer tersebut tidak jelas digambarkan, jadi analisisnya tidak dilakukan mengingat kemunculannya yang sangat minim.

\section{-Latar dalam Satua I Ubuh}

Unsur latar dapat dibedakan ke dalam tiga unsur pokok yaitu tempat, waktu, dan sosial. Latar tempat dalam Satua I Ubuh ini:di telabahe, di rompiokan, di tengah pasih, di umah I Kilap, dan di desa. Latar waktu pada suatu hari, petang, keesokan hari, latar suasana yaitu suasana menegangkan, suasana marah, dan suasana senang.

\section{-Latar dalam Satua Bagus Diarsa}

Latar yang dikaji pertama adalah latar tempat. Ada beberapa latar tempat dalam Satua Bagus Diarsayaitu:di bencingah, di umah Bagus Diarsa, di umah pekak (Ida Batara Siwa). Latar waktu malam hari, keesokan harinya. Latar suasana yaitu suasana menegangkan, suasana menyenangkan.

\section{-Tema dalam Satua I Ubuh}

Tema adalah ide sebuah cerita. Satua I Ubuh ini memiliki tema tradisional karena tergolong karya sastra tradisional dan dalam satua ini menampilkan hal yang paling mendasar dalam kehidupan yaitu mengajarkan kebaikan/kebenaran, 
bersahabat dengan semua makhluk ciptaanNya dan kesetiaan pada janji atau ucapan. Lebih spesifiknya, tema dalam Satua I Ubuh ini adalah "Satya Samaya atau setia terhadap janji”.

\section{-Tema dalam Satua Bagus Diarsa}

Satua Bagus Diarsa ini memiliki tema tradisional karena tergolong karya sastra tradisional dan dalam satua ini menampilkan hal yang paling mendasar dalam kehidupan yaitu mengajarkan kebaikan/kebenaran, menepati janji. Lebih spesifiknya, tema dalam Satua Bagus Diarsa ini adalah "Satya Samaya atau setia pada janji”.

\section{-Amanat dalam Satua I Ubuh}

Amanat adalah pesan yang ingin disampaikan oleh pengarang melalui sebuah karya sastra, dan sekaligus sebagai pemecahan atau jawaban dari pokok permasalahan dalam cerita. Amanat dapat disampaikan secara tersurat (eksplisit) maupun tersirat (implisit). Amanat dalam Satua I Ubuh ini menyiratkan bahwa sebagai seorang pemimpin harus bersikap arif dan bijaksana, mengemban amanah yang diterima dari masyarakatnya serta menepati janji yang telah diucapkan, karena janji adalah hutang.

\section{-Amanat dalam Satua Bagus Diarsa}

Kutipan tersebut menyiratkan suatu pesan atau amanat bahwa sebagai sesama makhluk ciptaan Tuhan, khususnya manusia kita hendaknya saling tolongmenolong antar sesama tanpa memandang latar belakang dari seseorang tersebut, menjadi seorang pemimpin yang jujur, dan janji yang diucapkan harus di tepati.

\section{Hubungan Intertekstual}

Hubungan intertekstual antara Satua I Ubuh dengan Satua Bagus Diarsa pada bagian ini dapat diungkap dengan melihat pertalian insiden, pertalian alur, pertalian tokoh, pertalian latar (tempat, waktu, dan suasana), pertalian tema, dan pertalian amanat. Selain itu, perbedaan-perbedaan yang terdapat antara kedua satua tersebut juga diungkap pada bagian ini.

\section{-Pertalian Insiden}

Pada Satua I Ubuh dengan Satua Bagus Diarsa memili hubungan atau pertalian. Hal itu ditunjukkan dari tokoh I Santeng pada satua I Ubuh dan I Bagus Diarsa pada satua Bagus Diarsa menjadi seorang pemimpin yang baru di desanya masing-masing. Diangkatnya tokoh I Santeng dan I Bagus Diarsa pada awalnya mereka mampu mengalahkan pemimpin yang sebelumnya, dan rakyatnya sangat segan dan simpati kepada I Santeng dan I Bagus Diarsa.

\section{-Pertalian Alur}

Alur Satua I Ubuh memiliki keterkaitan dengan Satua Bagus Diarsa yaitu menggunakan alur maju. Kedua tokoh dalam satua ini dilihat dari latar belakang kehidupan sebelumnya orang yang sederhana sehingga pada akhirnya menjadi orang yang berjaya di desanya masing-masing.

\section{-Pertalian Tokoh}

Tokoh utama dalam kedua satua ini yaitu tokoh I Santeng pada Satua I Ubuh dan I Bagus Diarsa pada Satua Bagus Diarsa, artinya sama-sama tokoh utamanya satu orang, sedangkan tokoh sekunder sama-sama berwujud Dewa dan seorang pemimpin di desa masingmasing, sedangkan tokoh komplementernya yaitu para panjak.

\section{-Pertalian Latar}

Pada kedua satua ini latar tempat yang ditunjukkan yaitu di suatu desa, baik dalam Satua I Ubuh maupun Satua Bagus Diarsa kedua tokoh ini (I Santeng dan I Bagus Diarsa) masing-masing mengalahkan pemimpin sebelumnya. Maka dari itu I Santeng dan I Bagus Diarsa diangkat oleh rakyatnya menjadi 
pemimpin yang baru di desanya masingmasing. Latar waktu yaitu sedek dina $a n u$, dan keesokan harinya. Latar suasana kedua satua ini suasana menegangkan dan menyenangkan.

\section{-Pertalian Tema}

Tema kedua satua ini menyiratkan tentang kesetiaan pada janji atau Satya Samaya. Pada Satua I Ubuh, I Kilap menepati janji yang pernah dikatakan kepada I Santeng bahwa apapun yang dimilikinya akan diserahkan kepada I Santeng bilamana I Santeng mau menerima I Kilap menjadi sahabatnya. Sedangkan pada Satua Bagus Diarsa sang kakek memenuhi janjinya kepada I Bagus Diarsa akan memberikan ayam peliharaannya.

\section{-Pertalian Amanat}

Amanat yang tersirat pada kedua satua ini yaitu mengandung nilai kesabaran dan ketekunan, tulus ikhlas dan rela berkorban, serta setia kepada janji. Selain nilai di atas juga terdapat nilai kebijaksanaan, mempunyai sikap yang disegani oleh rakyat sebagai pemimpin. Dari amanat yang tersirat dalam kedua satua ini dapat dijadikan sebagai pedoman dalam kehidupan sehari-hari.

\section{Perbedaan}

\section{-Perbedaan Insiden}

Satua I Ubuh awal pertemuan antara I Santeng dengan I Kilap saat umpan I Santeng habis namun tidak mendapatkan ikan, dikiranya I Kilap yang mencuri sehingga I Santeng marah dan ingin membunuh I Kilap. Sedangkan pada Satua Bagus Diarsa pertemuan antara I Bagus Diarsa dengan sang kakek saat I Bagus Diarsa sedang makan nasi di luar arena sabungan ayam dan dihampiri oleh sang kakek yang ingin meminta sisa makanan, namun I Bagus Diarsa menolak dan membelikan sang kakek makanan. Dilihat dari kutipan-kutipan di atas, tampak bahwa pada Satua I Ubuh sang punggawa mengendarai kuda putih bertanding melawan I Santeng hingga kalah dan meninggal, insiden pada Satua Bagus Diarsa ayam sakti I Bagus Diarsa yang mengalahkan Sang Prabhu hingga meninggal.

\section{-Perbedaan Tokoh}

Pada Satua I Ubuh I Kilap berubah menjadi seekor burung besar. Sedangkan pada Satua Bagus Diarsa, Ida Batara Siwa berubah menjadi seorang kakek. I Santeng adalah anak yatim piatu yang hanya mempunyai satu tetangga yang sering dipanggil kakek, sedangkan I Bagus Diarsa adalah seorang penjudi yang suka bermain ayam yang miskin dan sudah berkeluarga.

\section{-Perbedaan Latar}

Pada Satua I Ubuh latar tempat ditunjukkan ke dasar laut yaitu rumah I Kilap, sedangkan pada Satua Bagus Diarsa ditunjukkan ke bawah pohon beringin rumah Ida Batara Siwa.

\section{Simpulan}

Struktur yang membentuk Satua I Ubuh dan Satua Bagus Diarsa yaitu insiden, alur (menggunakan alur maju), tokoh dan penokohan (tokoh utama, tokoh sekunder, tokoh komplementer), latar (tempat, waktu, dan suasana), tema Satya Wacana, dan amanat yang tersirat yaitu dalam ajaran Hindu kesetiaan sangatlah penting di dalam berkepemimpinan maupun janji, maka dari itu janji harus ditepati. Hubungan intertekstual kedua satua ini pertalian insiden, pertalian alur, pertalian tokoh, pertalian latar, pertalian tema, dan pertalian amanat. Sedangkan perbedaannya yaitu perbedaan insiden, perbedaan tokoh, dan perbedaan latar.

\section{Daftar Pustaka}

Bagus, I Gusti Ngurah dkk. 1986. Dongeng Panji dalam Kesusastraan Bali, 
Pengantar, Teks. Terjemahan.

Departemen Pendidikan dan

Kebudayaan, Direktorat Jenderal

Kebudayaan, Proyek Penelitian dan

Pengkajian Kebudayaan (Baliologi).

Danandjaja,James.1984.Folklore

Indonesia Ilmu Gosip, Dongeng, dan lain-lain. Jakarta, Grafiti Press.

Nurgiyantoro, Burhan. 2009. Teori Pengkajian Fiksi. Yogyakarta, Gajah Mada.

Ratna, Nyoman Kutha. 2004. Teori, Metode, dan Teknik Penelitian Sastra. Yogyakarta, Pustaka Pelajar.

Tarigan, Henry Guntur. 1984. PrinsipPrinsip Dasar Sastra. Bandung, Angkasa. 